\title{
Research on Influence of Water-Cement Ratio on Reinforcement Effect for Permeation Grouting in Sand Layer
}

\author{
Zhipeng Li $\mathbb{D},{ }^{1}$ Lianzhen Zhang $\mathbb{D},{ }^{2}$ Yuntian Chu $\mathbb{D},{ }^{2}$ and Qingsong Zhang $\mathbb{D}^{3}$ \\ ${ }^{1}$ School of Transportation and Civil Engineering, Shandong Jiaotong University, Jinan, China \\ ${ }^{2}$ College of Pipeline and Civil Engineering, China University of Petroleum, Qingdao, China \\ ${ }^{3}$ Geotechnical and Structural Engineering Research Center, Shandong University, Jinan, China \\ Correspondence should be addressed to Lianzhen Zhang; zhanglianzhen@upc.edu.cn
}

Received 27 October 2019; Revised 10 February 2020; Accepted 15 February 2020; Published 9 March 2020

Academic Editor: Alain Portavoce

Copyright (C) 2020 Zhipeng Li et al. This is an open access article distributed under the Creative Commons Attribution License, which permits unrestricted use, distribution, and reproduction in any medium, provided the original work is properly cited.

In order to study permeation grouting reinforcement effect in the sand layer, a set of grouting test device is developed, which consists of a power device, a pressure-bearing slurry tank, and several test frames. Compressive strength, deformation modulus, and permeability coefficient are selected to be the evaluation index of grouting reinforcement effect. Grouting reinforcement effect under different water-cement ratio of cement slurry and curing time were measured. Eventually, under laboratory conditions, fitting formulas have been obtained which describe the quantitative relationship between reinforcement effect of permeation grouting and water-cement ratio and curing time. Results show that water-cement ratio of slurry has obvious effect on grouting reinforcement effect. Mechanical performance and impermeability of the grouted body are negative-correlated with water-cement ratio. There are two different destruction patterns for the grouted body in uniaxial compression process: global destruction pattern at low water-cement ratio and local destruction pattern at high water-cement ratio. If cement slurry at high water-cement ratio is permeated into the sand layer, water bleeding phenomena will appear and lead to inhomogeneous performance of the grouted body, with lower performance in the upper part and higher performance in the lower part of the grouted body.

\section{Introduction}

Grouting method [1-4] is the major technique used for sand layer reinforcement in geotechnical engineering. Better mechanical performance and better impermeability performance can be acquired after grouting operation. A lot of engineering projects indicate that the permeation grouting mode is the main grouting mode in gravel sand, coarse sand, and middle coarse sand. For the permeation grouting mode, slurry can permeate into the void space in the grouted medium without disturbing the original sand structure and form relatively homogeneous grouted body.

Many research studies have been done in aspect of permeation grouting in the sand layer. Yang et al. [5], Yang et al. [6], and Ye et al. [7] have established a theoretical model for permeation grouting considering time-dependent behavior of slurry viscosity, based on different fluid constitutive models (Newton model, Bingham model, and power law model). Zhang et al. [8] and Ye et al. [9] have developed the permeation grouting theoretical model for quick setting slurry, considering inhomogeneous distribution of slurry viscosity in the grouting area. Saada et al. [10], Yoon and El Mohtar [11], Axelsson et al. [12], and Kim et al. [13] studied filtration phenomenon in permeation grouting process and its internal mechanism affecting grouting process through theoretical and laboratory methods. In aspects of permeation grouting test, Yang et al. [14] analyzed influences of grouting pressure, grouting time, water-cement ratio, permeability coefficient, porosity upon grout diffusion radius, and concretion strength and their correlation by grouting simulation test in sandy gravels. Qian et al. [15] took the model experiment method to study permeability coefficient, porosity, and compressive strength of the porous medium before and after grouting operation with different effective diameters and fineness modulus. And permeability reduction law of chemical slurry for weakly porous media 
has been realized. Water-cement ratio has evident influence on slurry properties. Mozumder et al. [16] studied yield stress and plastic viscosity of microfine cement slurry at different water-cement ratios and came to the conclusion that yield stress and plastic viscosity are negative-correlated with water-cement ratio. Rahman et al. [17] analyzed influence of water-cement ratio and hydration time on rheological parameters using self-manufactured setup, resulting that yield stress increases with water-cement ratio decreasing and hydration time increasing. Li et al. [18] studied apparent viscosity of cement-sodium silicate grout, a typical quick setting grout, in setting process, and found that apparent viscosity of cement-sodium silicate grout would grow slower if water-cement ratio increases. Research studies above are important for studying permeation grouting in the sand layer. Above studies involve influence of water-cement ratio on grouting effect. However, most of them are concentrated on grouting diffusion. Few research studies have been conducted to realize quantitative influence of watercement ratio on grouting reinforcement effect. And the permeation grouting reinforcement mechanism at different water-cement ratios has not been studied adequately.

In order to solve problems mentioned above and quantify reinforcement effect of permeation grouting, a set of grouting test device is developed, which consists of a power device, a pressure-bearing slurry tank, and several test frames. This device can be directly used to measure permeability coefficient of the grouted body without form removal. Compressive strength, deformation modulus, and permeability coefficient are selected to be the evaluation index of grouting reinforcement effect. Grouting reinforcement effect under different water-cement ratios of cement slurry and curing time were measured. In the end, fitting formulas have been developed to quantitatively describe reinforcement effect for permeation grouting in the sand layer.

\section{Test Device, Materials, and Design of Experiment}

2.1. Grouting Test Device. Grouting test device consists of a power device, a pressure-bearing slurry tank, and several test frames. To inject slurry into the sand medium, compressed nitrogen is used as grouting power. Meanwhile, grouting pressure is constant during grouting process. Principle and photograph of the grouting test device are shown in Figures 1 and 2 .

(1) Power device uses the compressed nitrogen cylinder to provide grouting power. Nitrogen pressure stored in the compressed nitrogen cylinder is greater than $10 \mathrm{MPa}$. Pressure regulating valve is installed to control output nitrogen pressure, with output pressure greater than $3 \mathrm{MPa}$ which fits for the requirement of grouting test.

(2) Slurry tank has $10 \mathrm{~mm}$ thick wall. There is a detachable cover on top of the slurry tank, for cleaning the tank after grouting operation. Rubber gasket is set between the top cover and the tank to seal with the bolt. Slurry tank is connected with the compressed nitrogen cylinder. In the slurry tank, the upper space is filled with compressed nitrogen and the lower space is filled with slurry. Air pressure outputted by the compressed nitrogen cylinder is converted into slurry pressure to provide power for grouting process. A pressure gauge with measuring range of 0 to $3 \mathrm{MPa}$ is set on the top cover to monitor grouting pressure.

(3) Test frame consists of three parts: upper cover, middle steel pipe, and lower chassis, whose thickness is all $10 \mathrm{~mm}$ to meet high pressure-bearing requirements in grouting process. Middle steel pressure-bearing pipe is filled with the sand sample. A filter screen is set above the sand sample to prevent sand particles from moving. There is a permeable stone under the sand sample. Permeable stone has two roles: to restrict overall movement of the sand sample and to provide drainage passage for the air inside the sand sample during grouting process. Once water droplets appear at outfall of the test frame, the valve at lower chassis will be immediately closed. Sand sample is at standard size (height of $10 \mathrm{~cm}$ and diameter of $5 \mathrm{~cm}$ ). Steel pressure-bearing pipe is connected and fastened with the upper cover and lower chassis, using rubber gasket to ensure tightness of the device. In grouting process, slurry enters into the sand sample through the upper cover.

This grouting test device has three advantages: firstly, the size of the sand sample is at standard size, which is not only convenient for analysis of compressive strength of the grouted body but also has advantages of high repeatability and test efficiency; secondly, after the grouted body is being cured for a certain period without form removal, the test frame can be directly used to measure permeability coefficient of the grouted body; and thirdly, several grouting test frames can be connected at one time to realize simultaneous grouting of multiple samples, which greatly improves test efficiency.

\subsection{Measuring Device of Grouted Body Performance}

\subsubsection{Uniaxial Compression Test Equipment. When curing} time of the grouted body meets test requirements, grouted body is demolded by a manual stripper. Subsequently, uniaxial compression test is done to measure mechanical properties of the grouted body. Maximum loading force of the measuring machine is $100 \mathrm{kN}$, with testing process controlled by displacement. Grouted body of the sand layer with the permeation grouting mode is not fully homogeneous, leading to that the axial stress-strain curve is pretty coarse and there is no straight line portion in the axial stressstrain curve. As a result, traditional elastic modulus is not suitable to accurately describe deformation characteristics of the grouted body. In this paper, secant Young's modulus, the slope of a straight line joining the origin of the axial stress-strain curve to the peak point on the curve, is used to 


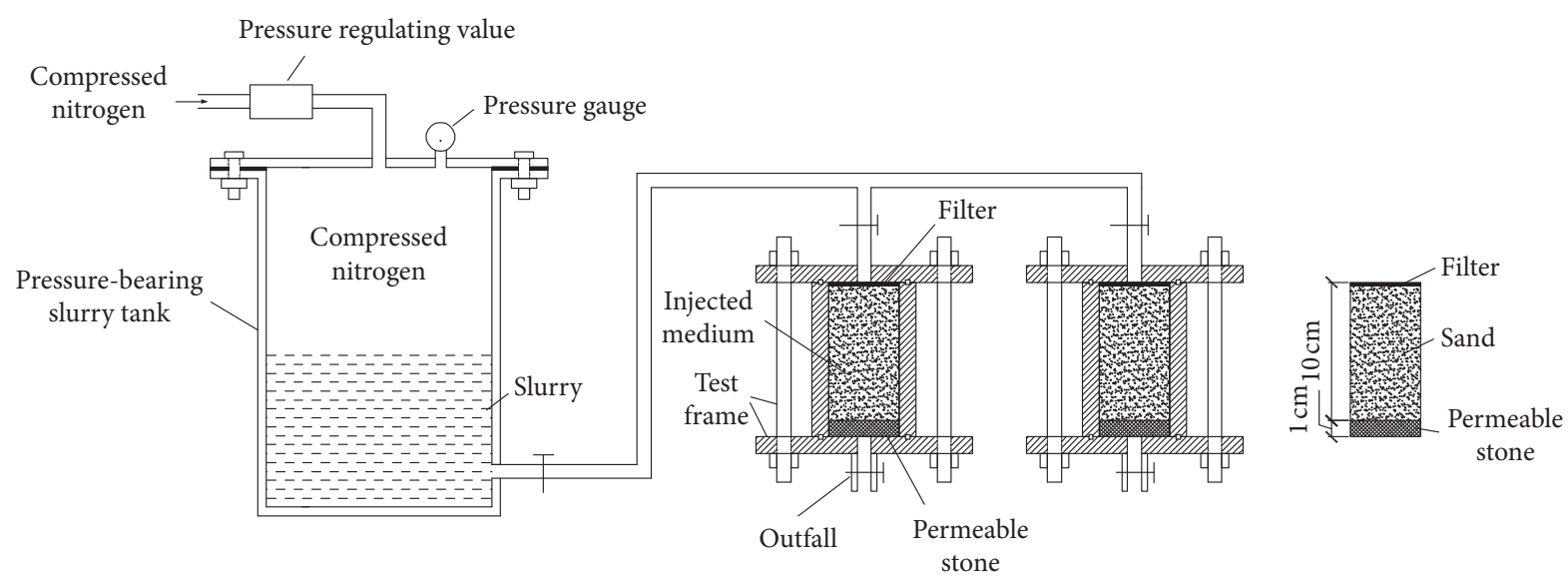

Figure 1: Principle of the grouting test device.

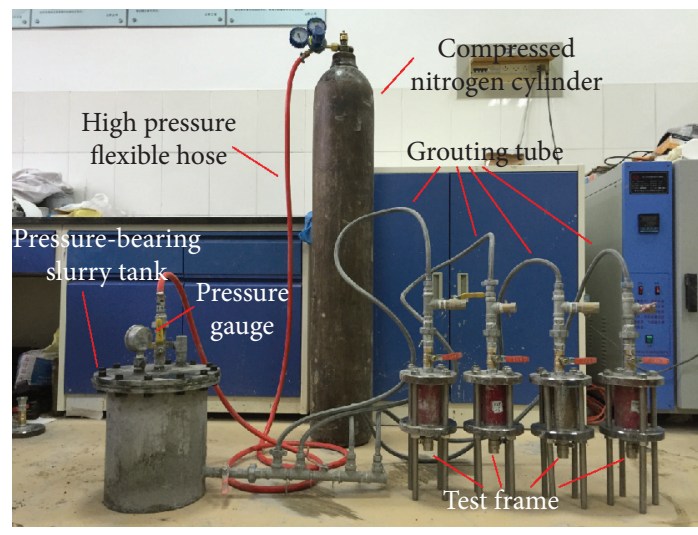

Figure 2: Photograph of the grouting test device.

describe deformation characteristics of the grouted body. Secant Young's modulus is called deformation modulus in this paper, as shown in the following equation [19]:

$$
E=\frac{\sigma_{c u}}{\varepsilon_{c u}},
$$

where $E$ is the deformation modulus, $\sigma_{c u}$ is the uniaxial compressive strength, and $\varepsilon_{c u}$ is the strain when the grouted body reaches maximum pressure.

\subsubsection{Permeability Coefficient Measuring Device. When} using the conventional permeability test device to measure permeability coefficient of the grouted body, it is generally difficult to ensure tightness between the grouted body and the inner wall of the test device. Therefore, test results of permeability coefficient of the grouted body are often inaccurate. In order to solve this problem, the grouted body is cured without form removal when measuring permeability coefficient in this paper so that tightness between the grouted body and the inner wall of the test device can be effectively ensured.

Permeability coefficient measuring device is shown in Figure 3 . The device includes an air compressor, a pressurebearing water tank, several test frames, and many pipelines. A certain amount of water is stored in the pressure-bearing

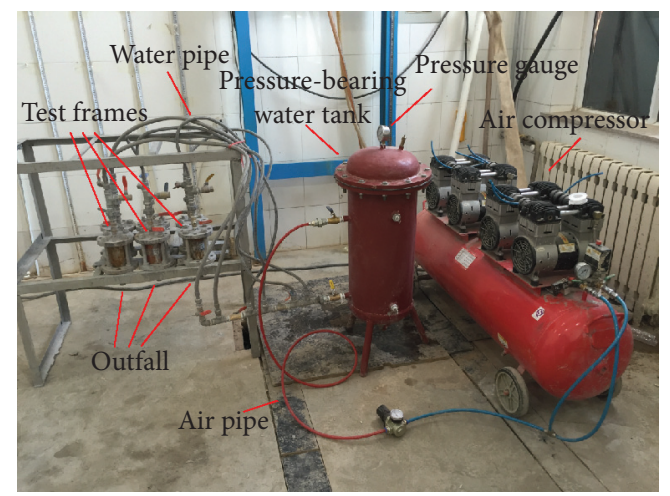

FIgUre 3: Permeability coefficient measuring device for the grouted body.

water tank. Pressure provided by the air compressor acts on water in the water tank and is converted into water pressure acting on one end of the grouted body. The other end of the grouted body is a free outflow end. Permeability coefficient of the grouted body can be obtained by measuring amount of water seepage in a period of time, combined with size of the grouted body and applied water pressure.

2.3. Experimental Materials. Purpose of sand permeation grouting is to improve mechanical properties and impermeability of the sand layer. Research studies conducted by Qian et al. [15] and Zhang [20] show that water-cement ratio is the main factor affecting permeation grouting effect. In this paper, common cement slurry with a water-cement ratio range of 0.8 to 1.6 is used. Basic physical and mechanical properties of cement used in this test are shown in Table 1.

According to previous studies on injectability of sand layers (Zhang [20], Mozumder et al. [16], and Markou et al. [21]), coarse sand and coarse-medium coarse sand have good injectability in which cement slurry can diffuse with the permeation mode. In this paper, coarse sand (particle size $1.25 \sim 2.5 \mathrm{~mm}$ ) and coarse-medium coarse sand (particle size $0.63 \sim 2.5 \mathrm{~mm}$ ) are used in test, whose basic physical parameters are shown in Table 2 . There is $0 \%$ and $4 \%$ cohesive soil in coarse sand and coarse-medium coarse sand, 
TABLE 1: Basic physical and mechanical properties of cement in test.

\begin{tabular}{lccccc}
\hline $\begin{array}{l}\text { Cement } \\
\text { grade }\end{array}$ & $\begin{array}{c}\text { Specific surface area } \\
\left(\mathrm{m}^{2} / \mathrm{kg}\right)\end{array}$ & $\begin{array}{c}\text { Initial setting time } \\
(\mathrm{h})\end{array}$ & $\begin{array}{c}\text { Final setting time } \\
(\mathrm{h})\end{array}$ & $\begin{array}{c}3 \mathrm{~d} \text { compressive strength } \\
(\mathrm{MPa})\end{array}$ & $\begin{array}{c}28 \mathrm{~d} \text { compressive strength } \\
(\mathrm{MPa})\end{array}$ \\
\hline $\mathrm{PO}_{42.5}$ & 385 & 15.1 & 21.5 & 4 & 13 \\
\hline
\end{tabular}

TABLE 2: Basic physical parameters of sand samples.

Sand particle size (mm) Cohesive soil content (\%) Water ratio (\%) Dry density $\left(\mathrm{g} / \mathrm{cm}^{3}\right)$ Void ratio (\%) Permeability coefficient

$1.25 \sim 2.5$

$0.63 \sim 2.5$

0

4

1.73

34.6

$(\mathrm{cm} / \mathrm{s})$

$3.432 \times 10^{-2}$

respectively. For these two kinds of sand samples, they have the same water ratio $(0 \%)$, dry density $\left(1.73 \mathrm{~g} / \mathrm{cm}^{3}\right)$, and void ratio $(34.6 \%)$.

2.4. Design of Experiment. In grouting process, grouting mode is the permeation mode, and duration time is two minutes.

According to grouting pressure range in actual sand grouting projects, grouting pressure is determined to be $1 \mathrm{MPa}$ in test.

After grouting operation, grouted body and grouting test frames are cured together, with a curing temperature of $20^{\circ} \mathrm{C}$ and humidity of $95 \%$. Curing time for the grouted body is determined to be $1 \mathrm{~d}, 3 \mathrm{~d}, 7 \mathrm{~d}, 14 \mathrm{~d}$, and $28 \mathrm{~d}$.

Grouting test process is greatly affected by human operation factors which may cause discrete results. In order to minimize impact of test operation error, each test is repeated 6 times. And average value of valid data is taken as final data after eliminating obvious abnormal data.

Relevant test parameters about slurry, sand sample, and grouting parameters are shown in Table 3.

\section{Analysis of Test Results}

3.1. Destruction Pattern of the Grouted Body. Demolded grouted bodies are shown in Figure 4. Cement slurry has permeated into the sand layer for all grouted bodies. Whole grouted bodies have good surface quality. Usability of the test device has been verified.

To a certain extent, destruction pattern reflects the reinforcement pattern and integrity of the grouted body. Uniaxial compression test results show that there are two typical destruction patterns corresponding to different water-cement ratios. When cement slurry with relatively low water-cement ratio permeated into the sand layer, global destruction pattern would happen. In the global destruction pattern (as shown in Figure 5), one or several fractures would go through the whole grouted body until failure of the grouted body. When cement slurry with high water-cement ratio permeated into the sand layer, local destruction pattern would happen. In this pattern (as shown in Figure 6), there exists expansion of the upper part of the grouted body, with lower part unchanged. When expansion of the upper part develops to a certain extent, whole grouted body will enter into the destruction stage.

As shown in Figure 5, with a water-cement ratio of 0.8 , one or several microfractures emerge on middle of the grouted body in the early stage of uniaxial compression test. Subsequently, fractures grow longer and wider as the grouted body is being compressed. In the end, fractures go through the whole grouted body, and failure of grouted body occurs. Global destruction pattern attributes to low watercement ratio $(\mathrm{W} / \mathrm{C}=0.8$ in Figure 5), which can hardly lead to water bleeding in the grouted body. In duration from end of grouting operation to initial setting of cement slurry, cement particles mainly maintain the respective stable position. In other words, there are few motions of cement particles when water-cement ratio is low, leading to homogeneous performance of the grouted body.

As shown in Figure 6, with a water-cement ratio of 1.6, there exists heterogeneity on the surface of the grouted body, with upper part coarse and alveolate and lower part smooth and dense. Expansion of the upper part of the grouted body occurs in the early stage of uniaxial compression test. Subsequently, expansion of the upper part develops further until the whole grouted body loses its bearing capacity. In the local destruction pattern, there occurs destruction in the upper part of the grouted body, and no damage in the lower part. Inhomogeneous performance of the grouted body attributes to high water-cement ratio (W/C $=1.6$ in Figure 6), which leads to water bleeding in the grouted body. Due to too much water in cement slurry, cement particles easily move vertically downward by gravity before initial setting of cement slurry, which we call it water bleeding phenomenon. In the upper part of the grouted body, there are less cement particles than those in the lower part. Therefore, degree of cement hydration reaction in the upper part is weaker than that in the lower part. Eventually, performance of the upper part is weaker than that of the lower part. In whole failure process, the upper part always comes into the failure phase earlier than the lower part.

\subsection{Effect of Water-Cement Ratio on Grouting Effect.} Relationship between $3 \mathrm{~d}$ compressive strength, $3 \mathrm{~d}$ deformation modulus, $1 \mathrm{~d}$ permeability coefficient of the grouted body and water-cement ratio is shown in Figure 7, with two typical media (coarse sand and coarse-medium coarse sand). 
TABLE 3: Relevant test parameters.

\begin{tabular}{|c|c|c|c|c|c|c|c|}
\hline $\begin{array}{l}\text { Water- } \\
\text { cement ratio }\end{array}$ & $\begin{array}{c}\text { Grouting } \\
\text { pressure }(\mathrm{MPa})\end{array}$ & $\begin{array}{c}\text { Grouting } \\
\text { duration time } \\
(\mathrm{min})\end{array}$ & Curing time & $\begin{array}{l}\text { Sand particle } \\
\text { size }(\mathrm{mm})\end{array}$ & $\begin{array}{l}\text { Dry density } \\
\left(\mathrm{g} / \mathrm{cm}^{3}\right)\end{array}$ & $\begin{array}{l}\text { Void ratio of sand } \\
\text { samples (\%) }\end{array}$ & $\begin{array}{l}\text { Size of sand } \\
\text { samples }\end{array}$ \\
\hline $0.8 \sim 1.6$ & 1 & 2 & $\begin{array}{c}1 \mathrm{~d}, 3 \mathrm{~d}, 7 \mathrm{~d} \\
14 \mathrm{~d}, 28 \mathrm{~d}\end{array}$ & $\begin{array}{l}1.25 \sim 2.5 \\
0.63 \sim 2.5\end{array}$ & 1.73 & 34.6 & $\begin{array}{l}\text { Height: } 10 \mathrm{~cm} \text {; } \\
\text { diameter: } 5 \mathrm{~cm}\end{array}$ \\
\hline
\end{tabular}

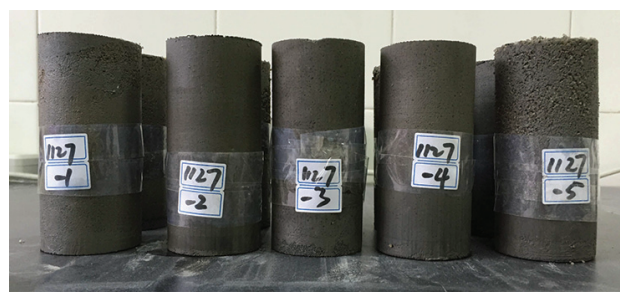

FIGURE 4: Demolded grouted body.

(1) As shown in Figures 7(a) and 7(b), water-cement ratio has a significant effect on $3 \mathrm{~d}$ compressive strength and $3 \mathrm{~d}$ deformation modulus of the grouted body. Change trend of $3 \mathrm{~d}$ compressive strength and $3 \mathrm{~d}$ deformation modulus with water-cement ratio is similar. They both decrease with water-cement ratio of slurry increasing. Change rate of $3 \mathrm{~d}$ compressive strength and $3 \mathrm{~d}$ deformation modulus with watercement ratio at low water-cement ratio is higher than that at high water-cement ratio.

(2) As shown in Figure 7(c), water-cement ratio is positively correlated with permeability coefficient of the grouted body. Permeability coefficient of the grouted body increases as water-cement ratio increases. Especially, permeability coefficient of the grouted body increases more significantly at high water-cement ratio than at low water-cement ratio. Compared with the grouted body at a water-cement ratio of 1.4, permeability coefficient of the grouted body at a water-cement ratio of 1.6 has increased by about $80 \%$.

In cement slurry, the amount of water which chemically reacts with the cement component is limited. Therefore, there exists extra water in the grouted body when using high water-cement ratio. Extra water would reduce mechanical performance and impermeability of the grouted body.

In actual sand permeation grouting projects, under the premise of meeting capabilities of grouting equipment, in order to acquire higher performance of the grouted body, cement slurry with low water-cement ratio should be used preferentially.

Filling degree of cement slurry in the void space of the sand medium and cement content determine grouting reinforcement effect. On the one hand, extra water which has not chemically reacted with the cement component at high water-cement ratio would reduce performance of the grouted body. On the other hand, high water-cement ratio can reduce viscosity resistance when cement slurry permeates into the void space of the sand medium and make grouting process more easy, which is beneficial for improving grouting reinforcement effect.
In this paper, effects of water-cement ratio on grouting reinforcement effect are explained from filling degree of whole slurry and cement particles in the void space of the sand medium. Two indexes, filling rate of slurry and effective filling rate of slurry, are defined, respectively. Filling rate of slurry refers to the percentage of whole slurry volume to void volume of the sand medium. Effective filling rate of slurry refers to the percentage of volume of the cement component to void volume of the sand medium. By weighing the sand medium before and after grouting operation, quality of injected slurry can be obtained. Further, volume of whole slurry and cement component can be acquired according to density of cement slurry and watercement ratio. Finally, filling rate of slurry and effective filling rate of slurry can be acquired at the same time. Void volume of the sample can be obtained by the following equation:

$$
V_{\text {void }}=V_{\text {total }}-\frac{m_{\text {sand }}}{\rho_{s}}
$$

where $V_{\text {void }}$ is the void volume of the sample and $V_{\text {total }}$ is the total volume of the sample $\left(V_{\text {total }}=\left(\pi D^{2} / 4\right) h\right) . D$ is inner diameter of the test frame, and $D$ is equal to $5 \mathrm{~cm} . h$ is inner height of the test frame, and $h$ is equal to $10 \mathrm{~cm} . m_{\text {sand }}$ is quality of the sand sample poured into the test frame. $\rho_{s}$ is density of sand particle, and $\rho_{s}$ is equal to $2.68 \mathrm{~kg} / \mathrm{m}^{3}$ in this test.

In equation (2), $V_{\text {total }}$ and $\rho_{s}$ are fixed for every test. Before every test, the quality of the sand sample poured into the test frame would be weighed. So, $V_{\text {void }}$ can be acquired accurately.

When curing time of the grouted body meets test requirements, the grouted body is demolded by a manual stripper. After demolding, the quality of the sand medium after grouting, which is the grouted body, would be weighed immediately.

For two typical sand media, variation of filling rate of slurry with water-cement ratio is shown in Figure 8.

(1) As shown in Figure 8, grouting filling rate varies from $88 \%$ to $99 \%$ for two sand media. In other words, slurry is almost filled with all void spaces in the sand medium. As water-cement ratio of slurry increases, filling rate increases and gradually approaches to $100 \%$. However, due to that filling rate of slurry is already around $90 \%$ at low water-cement ratio, increase of filling rate of slurry is not significant when water-cement ratio increases. It shows that increase of water-cement ratio of slurry is beneficial for injection of slurry, but improvement effect is not significant. 


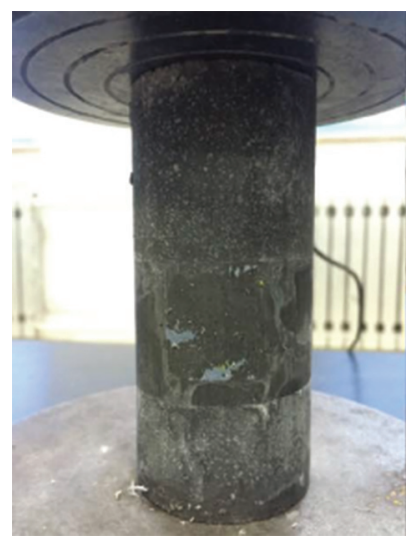

(a)

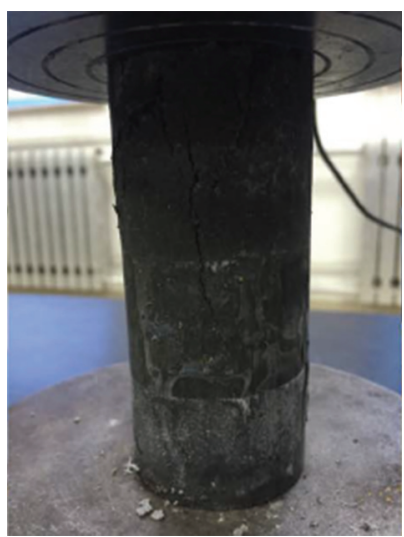

(b)

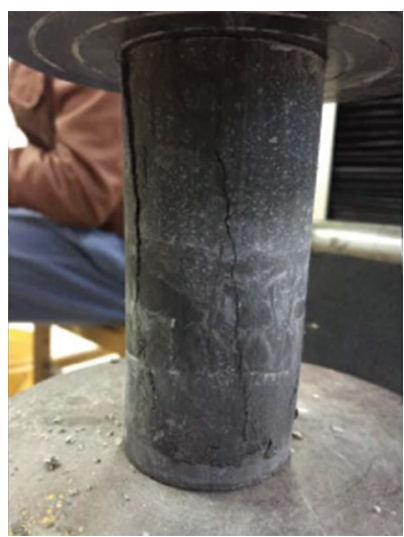

(c)

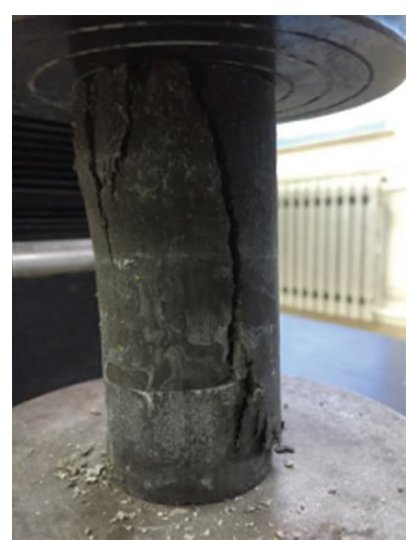

(d)

Figure 5: Global destruction pattern of the grouted body (W/C =0.8). (a) Initial state. (b) Fracture occurrence. (c) Fracture development. (d) Destruction.

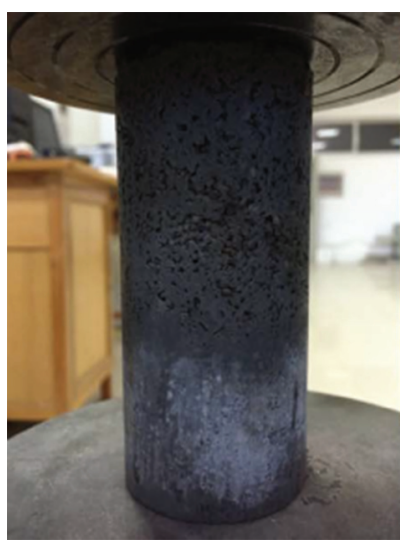

(a)

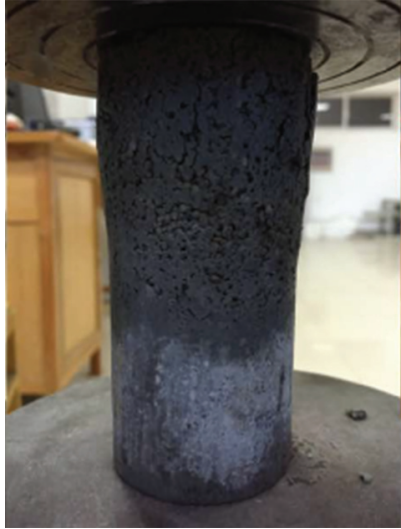

(b)

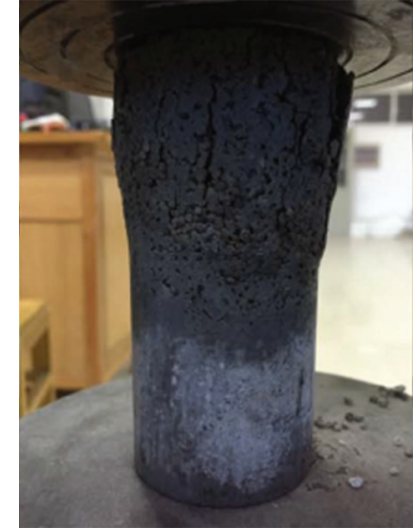

(c)

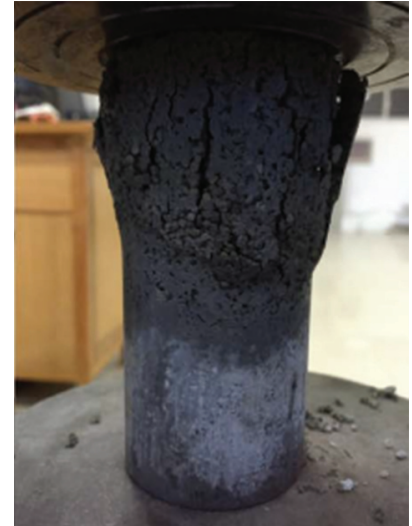

(d)

FIgURE 6: Local destruction pattern of the grouted body $(\mathrm{W} / \mathrm{C}=1.6)$. (a) Initial state. (b) Expansion of the upper part. (c) Expansion development. (d) Destruction.

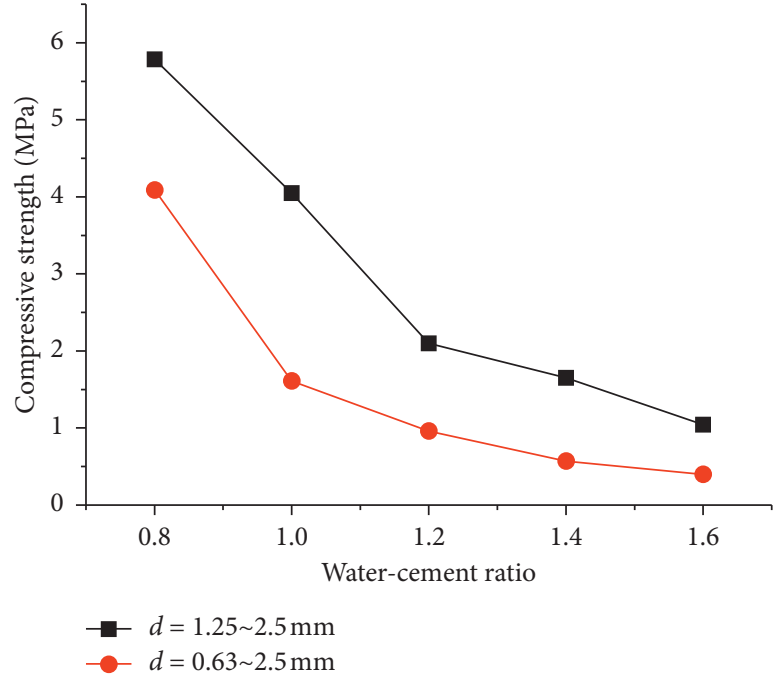

(a)

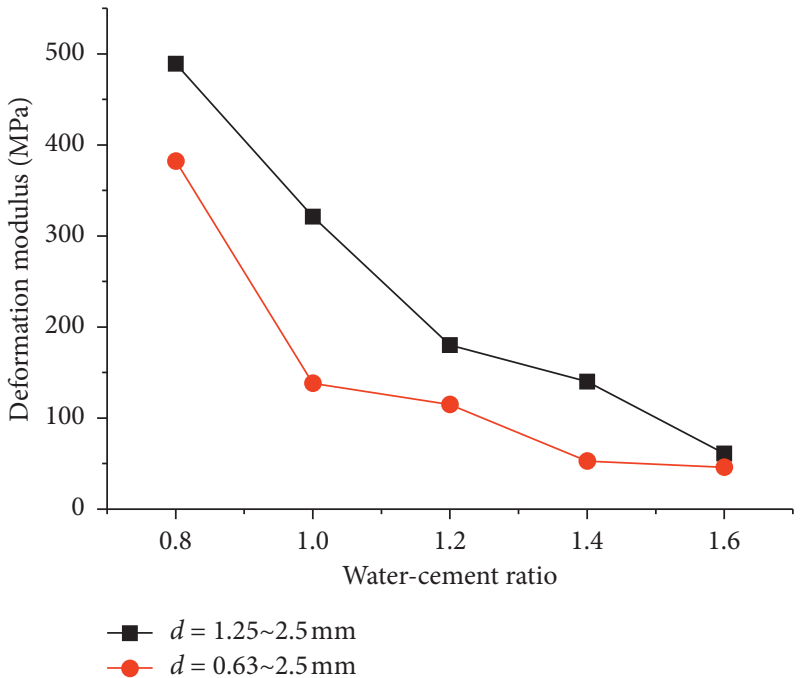

(b)

Figure 7: Continued. 


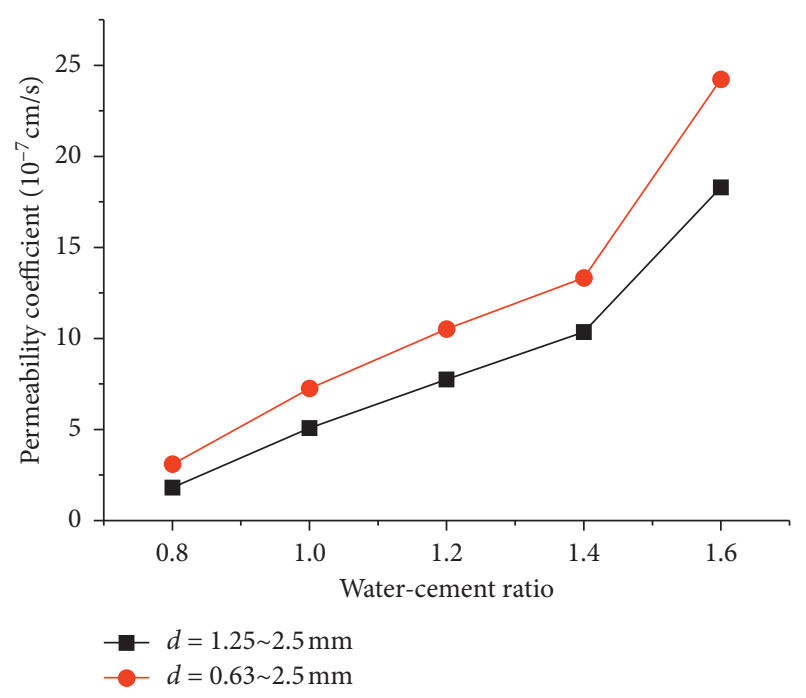

(c)

FiguRE 7: Influence of water-cement ratio on grouting effect in sand. (a) $3 \mathrm{~d}$ compressive strength. (b) $3 \mathrm{~d}$ deformation modulus. (c) $1 \mathrm{~d}$ permeability coefficient.

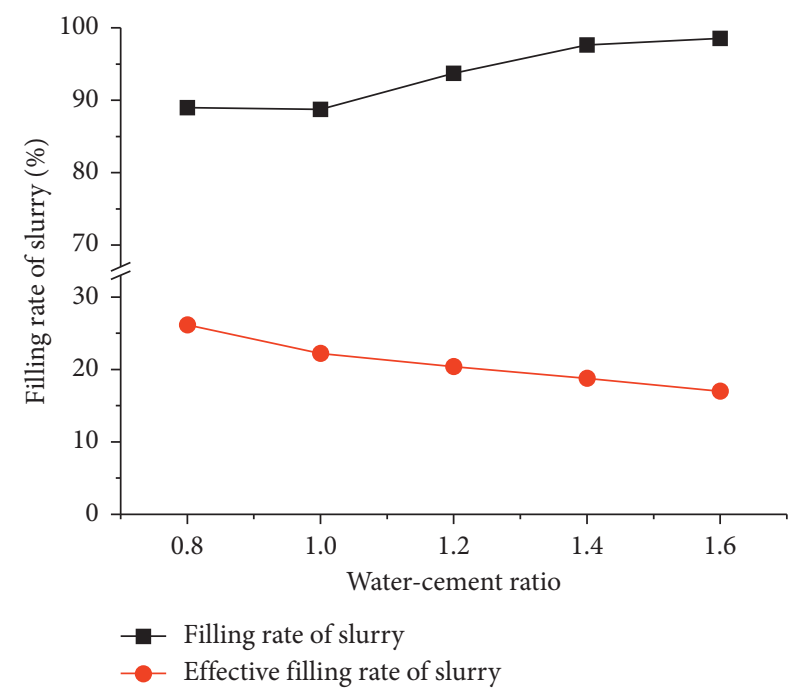

(a)

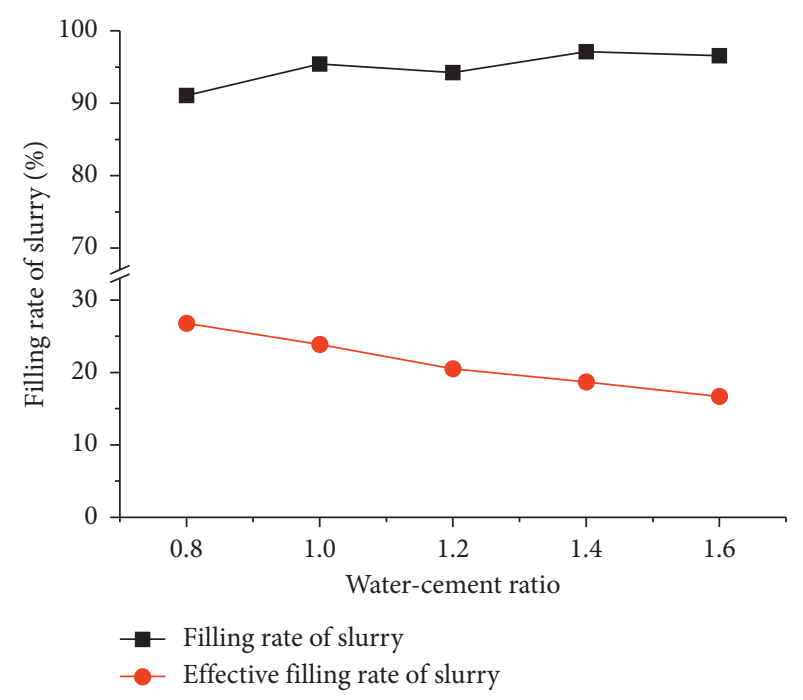

(b)

Figure 8: Variation of filling rate of slurry with water-cement ratio. (a) $d=0.63-2.5 \mathrm{~mm}$. (b) $d=1.25-2.5 \mathrm{~mm}$.

(2) Effective grouting filling rate varies from $16 \%$ to $27 \%$ for two sand media. Effective filling rate decreases with water-cement ratio increasing. With water-cement ratio increasing from 0.8 to 1.6 , effective filling rate of slurry decreases from about $26 \%$ to about $17 \%$. Effective filling rate of slurry is strongly affected by water-cement ratio.

Increase of water-cement ratio will significantly reduce the proportion of cement particles in slurry, resulting in decrease of amount of cement particles which fill in the void space of the sand medium. Although filling rate of slurry increases as water-cement ratio increases, the increase is relatively small, which is not enough to offset decrease of cement filling degree caused by increase of water-cement ratio. Finally, quality of cement particles filled in the void space of the sand medium decreases with water-cement ratio increasing. Filling degree of cement in the void space of the sand medium directly affects total amount of cement gel so that effective filling rate of slurry is the real index describing true filling degree of slurry. Although filling rate of slurry is low with low water-cement ratio, cement content in slurry is high, resulting in high effective filling rate. Grouting reinforcement effect of the grouted body at low water-cement ratio is better than that at high watercement ratio. Effective filling rate of slurry should be taken as an important reference index in actual grouting design of the sand layer.

There exist two valves at the upper cover and lower chassis of the test frame, respectively. Once grouting operation is ended, these two valves will be closed 
immediately. When the grouted body is being cured, these two valves are always closed. Therefore, no slurry can enter the test frame, and no slurry can go out of the test frame in curing duration. As a result, the total quality of the grouted body is always constant, and the total quality of slurry is always constant too. With the extension of curing time, cement particles would react with water and form cement gel. There would be three parts in slurry, which are water, cement particles, and cement gel. In curing process, the quality of water and the quality of cement particles will decrease simultaneously, and the quality of cement gel will increase. But, there is no need to exactly know how the quality of water changes and how the ratio of quality of water to quality of cement particles changes. Because even if we do not exactly know the law above, we can also know how reinforcement effect changes. If there are more cement particles injected into the void space of the sand sample, more cement gel would be created by gel reaction of water and cement particles. Further, the grouted body can acquire better performance. Therefore, as long as we obtain the effective filling rate of slurry, corresponding to the original quality of cement particles, we can know the reinforcement effect at specific curing time is good or bad. As a result, the influence of curing time on the quality change of water in slurry is not considered in this paper. And the mass and volume of cement in the sample in curing duration are not determined in this paper.

3.3. Law of Grouting Reinforcement Effect with Curing Time. In actual grouting projects, influenced by complex factors such as slurry gel reaction, groundwater environment, and construction disturbance, mechanical performance and impermeability of the grouted body of the sand layer change continuously with time. Change law of mechanical performance and impermeability with time has important guiding significance for grouting design. In this paper, mechanical performance and permeability coefficient of the grouted body with different curing times were measured. Measured results of compressive strength and deformation modulus of the grouted body for two typical sand media are shown in Figure 9.

As shown in Figure 9, compressive strength and deformation modulus of the grouted body increase with increase of curing time, and increase trends of two indexes are similar. With gel reaction of cement slurry continuing, mechanical performance of the grouted body increases basically linearly with curing time in a curing time range of $1 \mathrm{~d} \sim 14 \mathrm{~d}$. In a curing time range of $14 \mathrm{~d} \sim 28 \mathrm{~d}$, due to that cement slurry gel reaction has been basically completed, increasing range of mechanical performance is smaller than that in range of $1 \mathrm{~d} \sim 14 \mathrm{~d}$. In actual sand grouting projects, optimal excavation time should be synthetically determined by construction capacity and mechanical performance growth of the grouted body. Balance between construction safety and construction economy should be found.

Measured results of permeability coefficient of the grouted body for two typical sand media are shown in Figure 10.
As shown in Figure 10, difference between $3 \mathrm{~d}$ permeability coefficient and $1 \mathrm{~d}$ permeability coefficient is very significant. $1 \mathrm{~d}$ permeability coefficient is mostly in the order of $10^{-6} \sim 10^{-7} \mathrm{~cm} / \mathrm{s}$. By contrast, $3 \mathrm{~d}$ permeability coefficient of the grouted body for different sand media and watercement ratios is generally less than $3 \times 10^{-10} \mathrm{~cm} / \mathrm{s}$. Two days difference of curing time leads to a decrease of permeability coefficient by 3-4 orders of magnitude as compared to $1 \mathrm{~d}$ permeability coefficient. It can be seen that permeability coefficient of the grouted body decreases rapidly with curing time under laboratory curing condition. Since permeability coefficient is already at a low enough level which fully meets impermeability requirements of engineering rock and soil mass, permeability coefficient test for longer curing time has not been performed.

\section{Formula Fitting of Grouting Reinforcement Effect of the Sand Layer}

In order to make test results of permeation grouting reinforcement effect effectively guide grouting design in the sand layer, it is necessary to establish quantitative relationship between mechanical parameters of the grouted body and curing time and water-cement ratio of slurry. Quantitative relationship under laboratory conditions has been obtained by fitting experimental data.

Relationship between $3 \mathrm{~d}$ compressive strength, $3 \mathrm{~d}$ deformation modulus, $1 \mathrm{~d}$ permeability coefficient, and water-cement ratio of slurry can basically be described by exponential function. Exponential function form, $y=A e^{B(\mathrm{~W} / \mathrm{C})}+C$, is used to describe the relationship, where $y$ is $3 \mathrm{~d}$ compressive strength, $3 \mathrm{~d}$ deformation modulus, or $1 \mathrm{~d}$ permeability coefficient, W/C is water-cement ratio of slurry, and $A, B$, and $C$ are constants related to grouting pressure and sand characteristics, respectively. Fitting result corresponding to $P=1 \mathrm{MPa}, d=1.25-2.5 \mathrm{~mm}$, and $0 \%$ cohesive soil content is as follows:

$$
\left\{\begin{array}{l}
R_{3 \mathrm{~d}}=34.6 e^{-2.20(\mathrm{~W} / \mathrm{C})}-0.076 \\
E_{3 \mathrm{~d}}=2675.50 e^{-2.038(\mathrm{~W} / \mathrm{C})}-33.78, \\
K_{1 \mathrm{~d}}=0.637 e^{2.122(\mathrm{~W} / \mathrm{C})}-1.00
\end{array}\right.
$$

where $R_{3 \mathrm{~d}}$ is the $3 \mathrm{~d}$ compressive strength (unit: $\mathrm{MPa}$ ), $E_{3 \mathrm{~d}}$ is the $3 \mathrm{~d}$ deformation modulus (unit: $\mathrm{MPa}$ ), and $K_{1 \mathrm{~d}}$ is the $1 \mathrm{~d}$ permeability coefficient (unit: $10^{-7} \mathrm{~cm} / \mathrm{s}$ ).

Fitting result corresponding to $P=1 \mathrm{MPa}$, $d=0.63-2.5 \mathrm{~mm}$, and cohesive soil content of $4 \%$ is as follows:

$$
\left\{\begin{array}{l}
R_{3 \mathrm{~d}}=253.43 e^{-5.29(\mathrm{~W} / \mathrm{C})}+0.407 \\
E_{3 \mathrm{~d}}=34893.59 e^{-5.832(\mathrm{~W} / \mathrm{C})}+51.69 \\
K_{1 \mathrm{~d}}=0.440 e^{2.468(\mathrm{~W} / \mathrm{C})}+0.967
\end{array}\right.
$$

Applicable conditions of equations (3) and (4) are as follows: firstly, the sand layer is absolutely injectable so that cement slurry can permeate into the void space of the sand layer; secondly, water-cement ratio of slurry is in the range of 0.8 to 1.6 . 


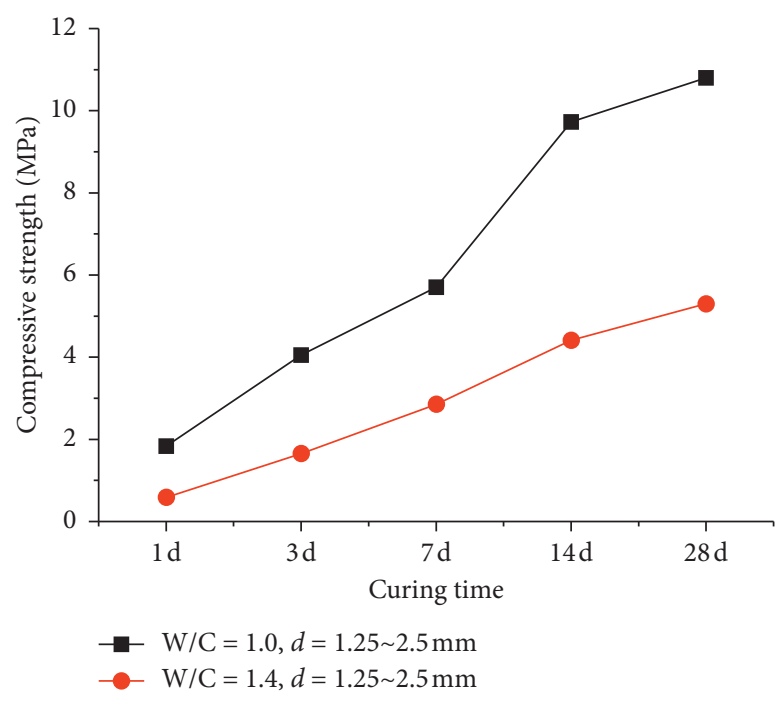

(a)

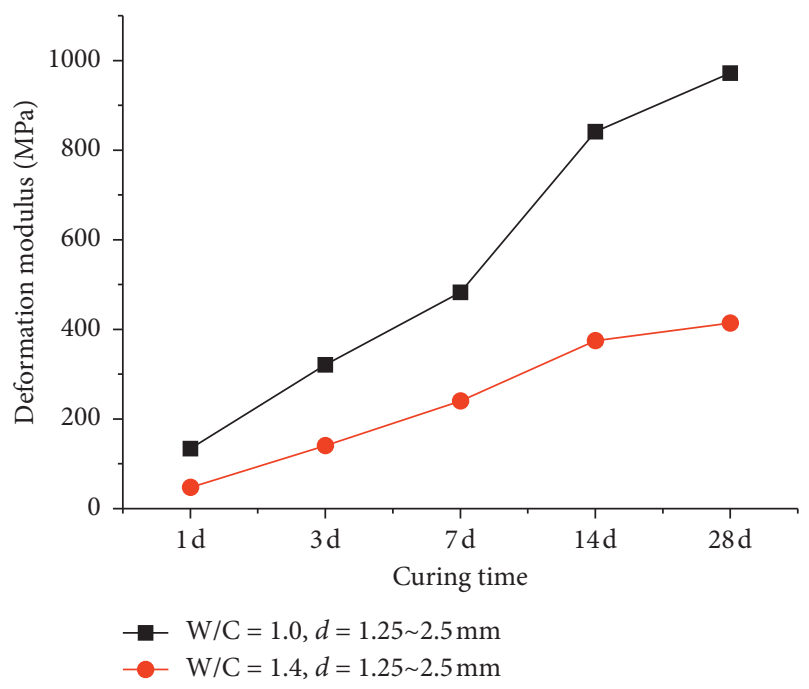

(b)

FIGURE 9: Variation of mechanical performance of the grouted body with curing time. (a) Compressive strength. (b) Deformation modulus.

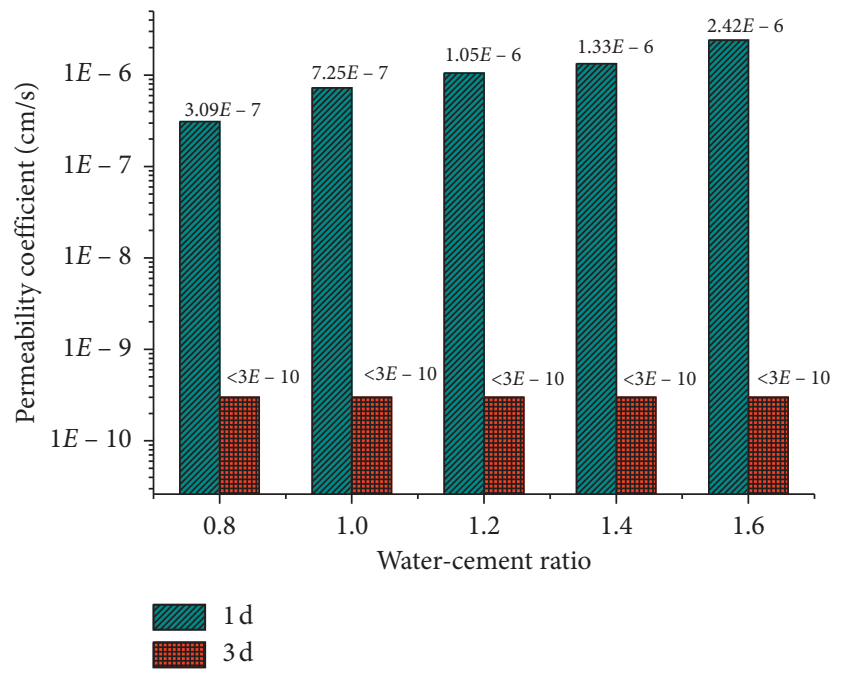

(a)

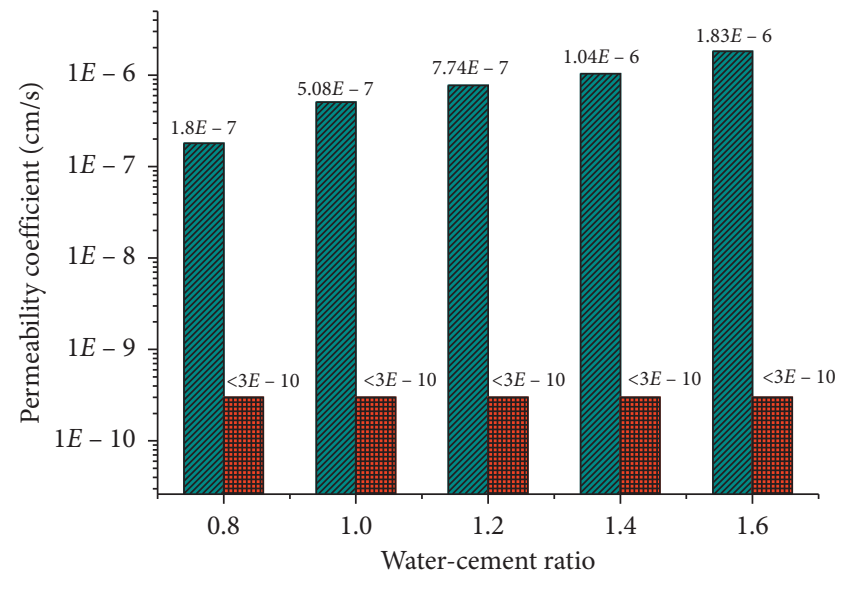

(b)

Figure 10: Variation of permeability coefficient of the grouted body with curing time. (a) $d=0.63-2.5 \mathrm{~mm}$. (b) $d=1.25-2.5 \mathrm{~mm}$.

Fitting curves of reinforcement effect of the grouted body and water-cement ratio are shown in Figure 11. Data fitting results are very similar to experimental test data, indicating that it is reasonable using exponential function to describe the relationship between reinforcement effect of sand grouting and water-cement ratio of slurry.

Change trend of compressive strength and deformation modulus with curing time is roughly similar to the power function form. Therefore, relationship between mechanical parameters and curing time is fitted by the power function form, $y=A t^{B}$, where $y$ indicates compressive strength or deformation modulus, $t$ is curing time; $A, B$ is constant, respectively. In order to make the formula form simple, $B$ is determined by 0.5 . Fitting result is as follows:

$$
\begin{cases}R=2.337 \sqrt{t}, & \mathrm{~W} / \mathrm{C}=1.0, \\ R=0.953 \sqrt{t}, & \mathrm{~W} / \mathrm{C}=1.4, \\ E=185.45 \sqrt{t}, & \mathrm{~W} / \mathrm{C}=1.0, \\ E=80.89 \sqrt{t}, & \mathrm{~W} / \mathrm{C}=1.4\end{cases}
$$

where $R$ is the compressive strength (unit: $\mathrm{MPa}$ ) and $E$ is the deformation modulus (unit: $\mathrm{MPa}$ ).

Fitting curves of mechanical parameters and curing time are shown in Figure 12, and its matching effect is satisfactory.

Comparing constant $A$ and $3 \mathrm{~d}$ compressive strength $R_{3 \mathrm{~d}}$ in fitting results of compressive strength, there exists following quantitative relationship: $A \approx\left(R_{3 \mathrm{~d}} / \sqrt{3}\right)$. At the same time, in fitting results of deformation modulus, there also 


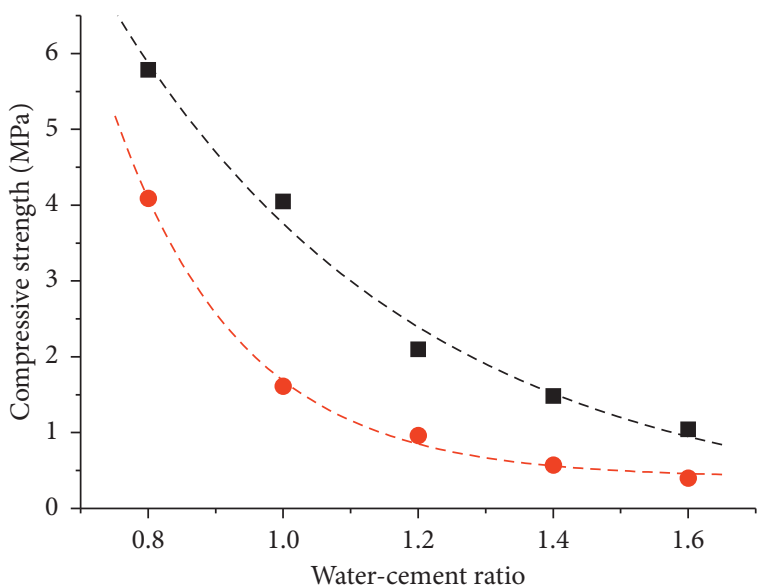

- $d=1.25 \sim 2.5 \mathrm{~mm}$ - $d=0.63 \sim 2.5 \mathrm{~mm}$

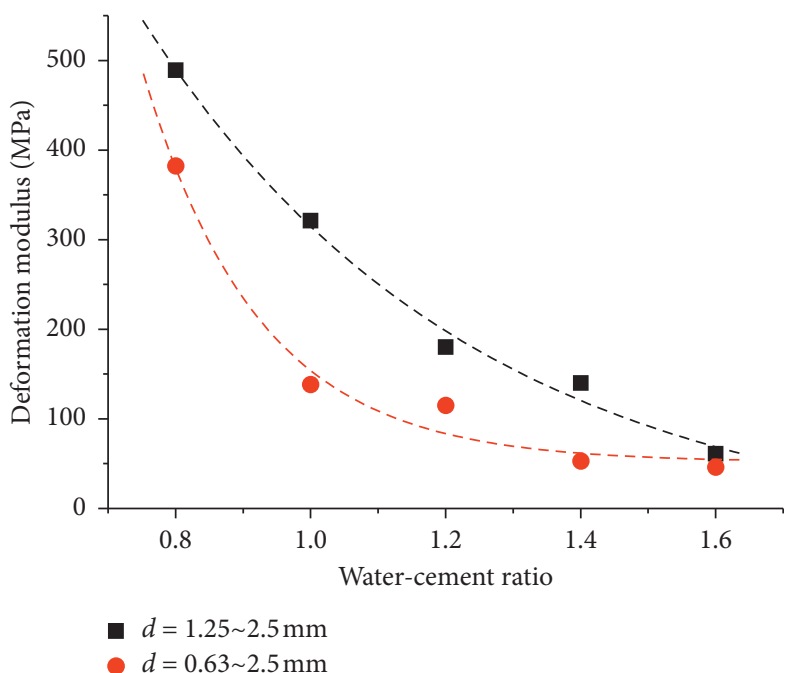

(b)

(a)

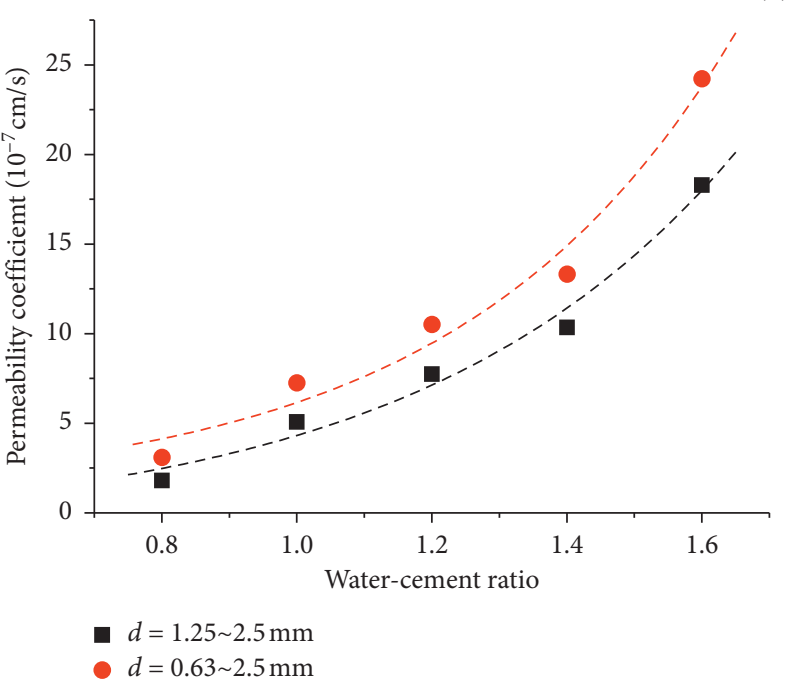

(c)

Figure 11: Fitting curves of reinforcement effect of the grouted body and water-cement ratio. (a) $3 \mathrm{~d}$ compressive strength. (b) $3 \mathrm{~d}$ deformation modulus. (c) $1 \mathrm{~d}$ permeability coefficient.

exists quantitative relationship between constant $A$ and $3 \mathrm{~d}$ deformation modulus: $A \approx\left(E_{3 \mathrm{~d}} / \sqrt{3}\right)$. It indicates that the relationship between mechanical parameters of the grouted body and curing time can be acquired if mechanical parameters of $3 \mathrm{~d}$ are known. Fitting formula of mechanical parameters of the grouted body and curing time can be described as

$$
\left\{\begin{array}{l}
R=\frac{R_{3 \mathrm{~d}}}{\sqrt{3}} \sqrt{t}, \\
E=\frac{E_{3 \mathrm{~d}}}{\sqrt{3}} \sqrt{t} .
\end{array}\right.
$$

As mentioned above, due to that permeability coefficient decreases rapidly with curing time, $3 \mathrm{~d}$ permeability coefficient can fulfil engineering requirements. In China, the requirement of permeability coefficient in the engineering is about $1 \times 10^{-6} \sim 1 \times 10^{-7} \mathrm{~cm} / \mathrm{s}$. And this standard is considered in this paper. It is not necessary to measure permeability coefficient of the grouted body with curing time longer than $3 \mathrm{~d}$. Therefore, the quantitative relationship between permeability coefficient and curing time has not fitted.

In summary, the relationship between mechanical parameters of the grouted body and water-cement ratio and curing time can be expressed as

$$
\Phi=\left(A e^{B(\mathrm{~W} / \mathrm{C})}+C\right) \sqrt{\frac{t}{3}}
$$

where $\Phi$ indicates compressive strength or deformation modulus of the grouted body (unit: MPa), W/C is the watercement ratio of cement slurry, $t$ is the curing time (d), and $A$, $B$, and $C$ are constants, respectively, which are determined by grouting pressure and sand characteristics. 


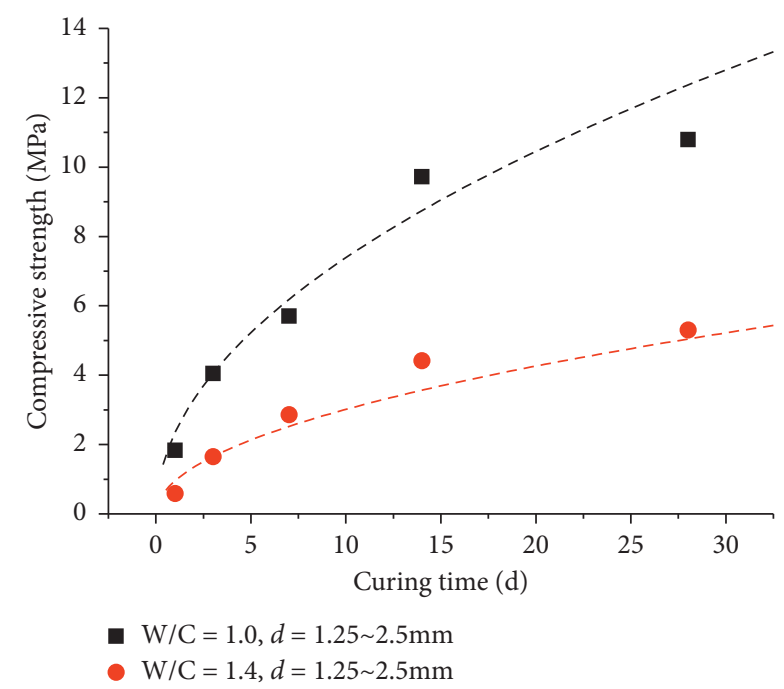

(a)

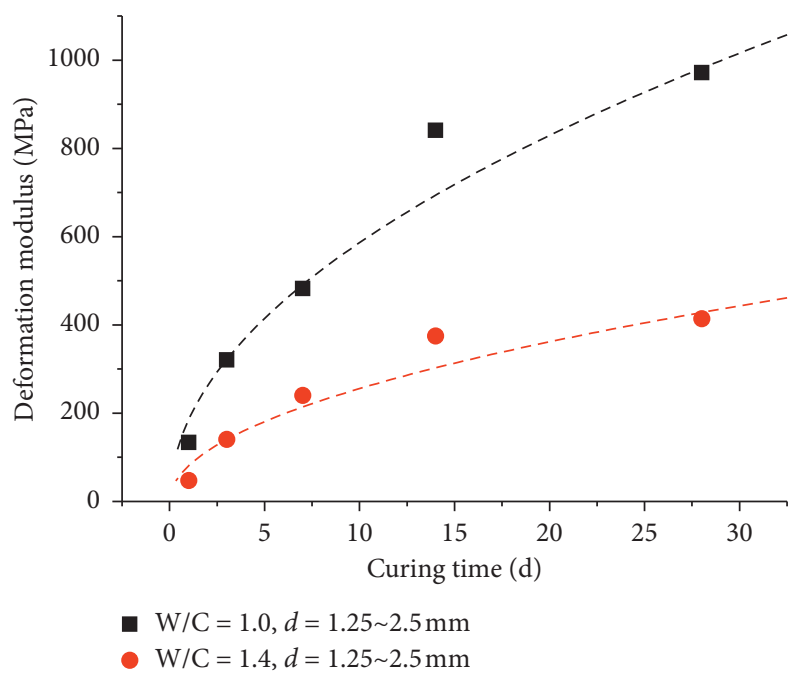

(b)

FIGURE 12: Fitting curves of mechanical parameters of the grouted body and curing time. (a) Compressive strength. (b) Deformation modulus.

Relationship between permeability coefficient of the grouted body and water-cement ratio and curing time can be expressed as

$$
K= \begin{cases}A e^{B(\mathrm{~W} / \mathrm{C})}+C, & t=1 \mathrm{~d} \\ <3 \times 10^{-10} \mathrm{~cm} / \mathrm{s}, & t \geq 3 \mathrm{~d}\end{cases}
$$

where $K$ is the permeability coefficient (unit: $10^{-7} \mathrm{~cm} / \mathrm{s}$ ), W/ $\mathrm{C}$ is the water-cement ratio of slurry, and $A, B$, and $C$ are constants, respectively. When curing time is more than $3 \mathrm{~d}$, permeability coefficient of the grouted body is less than $3 \times 10^{-10} \mathrm{~cm} / \mathrm{s}$.

Applicable conditions of equations (7) and (8) are as follows: firstly, the sand layer is absolutely injectable; secondly, water-cement ratio of slurry is in the range of 0.8 to 1.6; and thirdly, curing time of the grouted body of the sand layer is in the range of $1 \mathrm{~d}$ to $28 \mathrm{~d}$.

In this paper, constants $A, B$, and $C$ in fitting formulas are not physically significant. In other words, these constants are merely statistically significant. Constants $A, B$, and $C$ are indeed related to grouting pressure and sand characteristics. However, only one grouting pressure $(1 \mathrm{MPa})$ and two sand graduations $(1.25 \sim 2.5 \mathrm{~mm}$ and $0.63 \sim 2.5 \mathrm{~mm}$ ) have been studied in this test, and it is hard to acquire the relationship between constants $A, B$, and $C$ and grouting pressure, sand characteristics. In future, deeper research should be done.

\section{Conclusion}

Influence of water-cement ratio on reinforcement effect for permeation grouting in the sand layer is quantitatively tested and analyzed in this study. Conclusions are as follows.

A set of grouting test device is developed, which can simulate permeation grouting reinforcement effect in the sand layer. It consists of a power device, a pressure-bearing slurry tank, and several test frames. This device can be directly used to measure permeability coefficient of the grouted body without form removal. In addition, several grouting test frames can be connected at one time to realize simultaneous grouting of multiple samples, which greatly improves test efficiency.

Water-cement ratio of slurry has obvious effect on grouting reinforcement effect for the sand layer. When water-cement ratio of slurry increases, compressive strength, deformation modulus, and impermeability of the grouted body reduce significantly. There are two different destruction patterns for the grouted body in uniaxial compression process: global destruction pattern at low water-cement ratio and local destruction pattern at high water-cement ratio. When using cement slurry at high water-cement ratio for permeation grouting, water bleeding phenomena will appear and lead to inhomogeneous performance of the grouted body, with lower performance in the upper part and higher performance in the lower part of the grouted body.

Quantitative fitting formulas under laboratory conditions have been obtained that can describe the relationship between reinforcement effect of permeation grouting and water-cement ratio and curing time. Permeation grouting reinforcement effect on the sand layer can be predicted using these fitting formulas.

\section{Data Availability}

The data used to support the findings of this study are available from the corresponding author upon request.

\section{Conflicts of Interest}

The authors declare that they have no conflicts of interest.

\section{Acknowledgments}

This work was supported by the National Natural Science Foundation of China (grant numbers 51909270 and 
51909147), the Fundamental Research Funds for the Central Universities (grant number 18CX02003A), and the Natural Science Foundation of Shandong Province (grant number ZR2018BEE035).

\section{References}

[1] S. Li, R. Liu, Q. Zhang, and X. Zhang, "Protection against water or mud inrush in tunnels by grouting: a review," Journal of Rock Mechanics and Geotechnical Engineering, vol. 8, no. 5, pp. 753-766, 2016.

[2] Z. Zhou, X. Cai, X. Du, S. Wang, D. Ma, and H. Zang, "Strength and filtration stability of cement grouts in porous media," Tunnelling and Underground Space Technology, vol. 89, pp. 1-9, 2019.

[3] Q. Wang, S. Wang, S. W. Sloan, D. Sheng, and R. Pakzad, "Experimental investigation of pressure grouting in sand," Soils and Foundations, vol. 56, no. 2, pp. 161-173, 2016.

[4] Y. Gao and W. H. Sui, "Modelling of chemical grout column permeated by water in transparent soil," International Journal of Environment and Pollution, vol. 59, no. 2-4, pp. 142-154, 2016.

[5] Z. Yang, K. Hou, T. Guo et al., "Study on penetration grouting mechanism based on Bingham fluid of time-dependent behavior," Journal of Sichuan University (Engineering Science Edition), vol. 43, no. S1, pp. 67-72, 2011, in Chinese.

[6] X. Yang, J. Lei, L. Xia et al., "Study on grouting diffusion radius of exponential fluids," Rock and Soil Mechanics, vol. 26, no. 11, pp. 112-115, 2005, in Chinese.

[7] F. Ye, C. Gou, Y. Liu et al., "Half-spherical surface diffusion model of shield tunnel back-filled grouts," Journal of Tongji University (Natural Science), vol. 40, no. 12, pp. 1789-1794, 2012, in Chinese.

[8] L. Zhang, Q. Zhang, R. Liu et al., "Penetration grouting mechanism of quick setting slurry considering spatiotemporal variation of viscosity," Rock and Soil Mechanics, vol. 38, no. 2, pp. 443-452, 2017, in Chinese.

[9] F. Ye, C. Sun, J. Mao et al., "Analysis on grouting mechanism for shield tunnel segment by cement and sodium silicate mixed grout in consideration of time-dependency and space effect of viscosity," China Journal of Highway and Transport, vol. 30, no. 8, pp. 49-56, 2017, in Chinese.

[10] Z. Saada, J. Canou, L. Dormieux, J. C. Dupla, and S. Maghous, "Modelling of cement suspension flow in granular porous media," International Journal for Numerical and Analytical Methods in Geomechanics, vol. 29, no. 7, pp. 691-711, 2005.

[11] J. Yoon and C. S. El Mohtar, "A filtration model for evaluating maximum penetration distance of bentonite grout through granular soils," Computers and Geotechnics, vol. 65, pp. 291301, 2015.

[12] M. Axelsson, G. Gustafson, and A. Fransson, "Stop mechanism for cementitious grouts at different water-to-cement ratios," Tunnelling and Underground Space Technology, vol. 24, no. 4, pp. 390-397, 2009.

[13] J.-S. Kim, I.-M. Lee, J.-H. Jang, and H. Choi, "Groutability of cement-based grout with consideration of viscosity and filtration phenomenon," International Journal for Numerical and Analytical Methods in Geomechanics, vol. 33, no. 16, pp. 1771-1797, 2009.

[14] P. Yang, Y. Tang, Z. Peng et al., "Study on grouting simulating experiment in sandy gravels," Chinese Journal of Geotechnical Engineering, vol. 28, no. 12, pp. 2134-2138, 2006, in Chinese.

[15] Z. Qian, Z. Jiang, L. Cao et al., "Experiment study of penetration grouting model for weakly cemented porous media,"
Rock and Soil Mechanics, vol. 34, no. 1, pp. 139-143, 2013, in Chinese.

[16] R. A. Mozumder, A. I. Laskar, and M. Hussain, "Penetrability prediction of microfine cement grout in granular soil using artificial intelligence techniques," Tunnelling and Underground Space Technology, vol. 72, pp. 131-144, 2018.

[17] M. Rahman, U. Håkansson, and J. Wiklund, "In-line rheological measurements of cement grouts: effects of water/cement ratio and hydration," Tunnelling and Underground Space Technology, vol. 45, pp. 34-42, 2015.

[18] S. Li, W. Han, Q. Zhang et al., "Research on time-dependent behavior of viscosity of fast curing grouts in underground construction grouting," Chinese Journal of Rock Mechanics and Engineering, vol. 32, no. 1, pp. 1-7, 2013, in Chinese.

[19] B. H. G. Brady and E. T. Brown, Rock Mechanics for Underground Mining, Springer Press, Berlin, Germany, 3rd edition, 1985.

[20] L. Zhang, Study on Penetration and Reinforcement Mechanism of Grouting in Sand Layer Disclosed by Subway Tunnel and Its Application, Shandong University, Jinan, China, 2017.

[21] I. N. Markou, D. N. Christodoulou, E. S. Petala, and D. K. Atmatzidis, "Injectability of microfine cement grouts into limestone sands with different gradations: experimental investigation and prediction," Geotechnical and Geological Engineering, vol. 52, pp. 868-882, 2017. 